\title{
RESEARCH
}

Open Access

\section{Development of a CD19 PET tracer for detecting $B$ cells in a mouse model of multiple sclerosis}

Marc Y. Stevens ${ }^{1 \dagger} \mathbb{D}$, Haley C. Cropper ${ }^{1 \dagger} \mathbb{D}$, Katherine L. Lucot ${ }^{2}$, Aisling M. Chaney ${ }^{1}$, Kendra J. Lechtenberg ${ }^{3}$, Isaac M. Jackson ${ }^{1}$, Marion S. Buckwalter ${ }^{3}$ and Michelle L. James ${ }^{1,3^{*}}$

\begin{abstract}
Background: B cells play a central role in multiple sclerosis (MS) through production of injurious antibodies, secretion of pro-inflammatory cytokines, and antigen presentation. The therapeutic success of monoclonal antibodies (mAbs) targeting B cells in some but not all individuals suffering from MS highlights the need for a method to stratify patients and monitor response to treatments in real-time. Herein, we describe the development of the first CD19 positron emission tomography (PET) tracer, and its evaluation in a rodent model of MS, experimental autoimmune encephalomyelitis (EAE).
\end{abstract}

Methods: Female C57BL/6 J mice were induced with EAE through immunization with myelin oligodendrocyte glycoprotein $\left(\mathrm{MOG}_{1-125}\right)$. PET imaging of naïve and EAE mice was performed $19 \mathrm{~h}$ after administration of $\left[{ }^{64} \mathrm{Cu}\right] \mathrm{CD} 19-\mathrm{mAb}$. Thereafter, radioactivity in organs of interest was determined by gamma counting, followed by ex vivo autoradiography of central nervous system (CNS) tissues. Anti-CD45R (B220) immunostaining of brain tissue from EAE and naïve mice was also conducted.

Results: Radiolabelling of DOTA-conjugated CD19-mAb with ${ }^{64} \mathrm{Cu}$ was achieved with a radiochemical purity of 99\% and molar activity of $2 \mathrm{GBq} / \mu \mathrm{mol}$. Quantitation of CD19 PET images revealed significantly higher tracer binding in whole brain of EAE compared to naive mice ( $2.02 \pm 0.092$ vs. $1.68 \pm 0.06$ percentage of injected dose per gram, \% $\mathrm{ID} / \mathrm{g}, p=0.0173)$. PET findings were confirmed by ex vivo gamma counting of perfused brain tissue $(0.22 \pm 0.020$ vs. $0.12 \pm 0.003 \% \mathrm{ID} / \mathrm{g}, p=0.0010$ ). Moreover, ex vivo autoradiography of brain sections corresponded with PET imaging results and the spatial distribution of B cells observed in B220 immunohistochemistry-providing further evidence that $\left[{ }^{64} \mathrm{Cu}\right] \mathrm{CD} 19-\mathrm{mAb}$ enables visualization of $\mathrm{B}$ cell infiltration into the CNS of EAE mice.

Conclusion: CD19-PET imaging can be used to detect elevated levels of B cells in the CNS of EAE mice, and has the potential to impact the way we study, monitor, and treat clinical MS.

Keywords: PET, Multiple sclerosis, EAE mice, B cells, CD19

\footnotetext{
*Correspondence: mljames@stanford.edu

${ }^{+}$Marc Y. Stevens and Haley C. Cropper contributed equally to this work. 'Department of Radiology, Molecular Imaging Program at Stanford, 1201 Welch Rd, Stanford, CA 94305, USA

${ }^{3}$ Department of Neurology \& Neurological Sciences, Stanford University, Stanford, CA, USA

Full list of author information is available at the end of the article
}

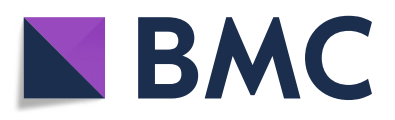

(- The Author(s). 2020 Open Access This article is licensed under a Creative Commons Attribution 4.0 International License, which permits use, sharing, adaptation, distribution and reproduction in any medium or format, as long as you give appropriate credit to the original author(s) and the source, provide a link to the Creative Commons licence, and indicate if changes were made. The images or other third party material in this article are included in the article's Creative Commons licence, unless indicated otherwise in a credit line to the material. If material is not included in the article's Creative Commons licence and your intended use is not permitted by statutory regulation or exceeds the permitted use, you will need to obtain permission directly from the copyright holder. To view a copy of this licence, visit http://creativecommons.org/licenses/by/4.0/. The Creative Commons Public Domain Dedication waiver (http://creativecommons.org/publicdomain/zero/1.0/) applies to the data made available in this article, unless otherwise stated in a credit line to the data. 


\section{Background}

Multiple sclerosis (MS) is a chronic, immune-mediated, neurological disease, characterized by the presence of demyelinating lesions in the brain and spinal cord, and progressive physical and cognitive disability [1]. Nearly 1 million people have MS in the USA alone, with 200 new cases diagnosed each week [2]. Although a variety of disease-modifying therapies [3] exist for the most common type of MS, relapsing-remitting MS (RRMS), disease manifestation is highly heterogeneous and treatment response is variable. Current standard-of-care imaging techniques used to clinically diagnose and monitor MS focus on magnetic resonance imaging (MRI) to identify lesions in the central nervous system (CNS). However, this diagnostic approach lacks molecular information regarding an individual's immune signature in the whole body and brain.

MS has traditionally been viewed as a $\mathrm{T}$ cell-mediated disease, but the critical role of B lymphocytes has become increasingly apparent, as demonstrated by the striking success of B cell-depleting therapies in clinical trials. Rituximab and ocrelizumab, which both target the B cell surface antigen CD20, have been shown to dramatically reduce the annualized relapse rate and delay disability progression in RRMS [4]. More recently, newer B cell therapies have been developed that target CD19; a pan-B cell surface marker expressed across a broader range of $B$ cell subsets than CD20 [5]. One such example is inebilizumab [6], which demonstrated favorable safety and tolerability in a phase I MS trial and marked efficacy in neuromyelitis optica (NMO), another immune-mediated CNS disease affecting the spinal cord and optical nerve [7, 8]. Although these promising B cell-targeted therapies exist, there is currently no way to accurately select patients for these treatments or to quantify their effects on B cell load in the CNS and peripheral organs.

Positron emission tomography (PET) has the potential to answer these questions by providing highly specific, quantitative information regarding the in vivo distribution and burden of B cells in the periphery and CNS. However, no gold-standard PET tracer for B cells in MS currently exists. PET tracers for CD19 and CD20 could reveal clinically relevant information regarding different aspects of B cell biology. Recently, our laboratory reported the use of $\left[{ }^{64} \mathrm{Cu}\right]$-rituximab as an imaging agent in a mouse model of MS, showing that $\mathrm{CD} 20^{+} \mathrm{B}$ cells can be detected in vivo in the CNS of transgenic mice expressing human CD20 [9]. Although this data is encouraging, the therapeutic monoclonal antibody depleted $B$ cells in vivo, limiting the amount of tracer that could be administered, and therefore the overall sensitivity of the method.

A separate clinical study with ${ }^{89} \mathrm{Zr}$-labeled rituximab focused on quantitation of cerebral binding of the radiolabelled antibody in RRMS patients, following predosing with the therapeutic antibody [10]. Radiolabelled rituximab was not detected in the brain parenchyma, possibly due to saturation of binding sites by the isotopically unmodified rituximab administered for therapeutic purposes. Alternatively, the lack of signal could have been due to CD20 not being expressed by plasmablasts and plasma cells known to be present in the CNS of MS patients $[11,12]$.

In contrast to CD20-targeting tracers, a PET tracer for CD19 would provide a major advantage because of its potential to detect a broader range of B cell subsets, including pro-B cells, antibody-secreting plasmablasts, circulating plasma cells, and a subset of plasma cells in the bone marrow. Importantly, CD19 does not appear to undergo internalization and is not expressed on $\mathrm{T}$ cells (whereas CD20 is), making it a more attractive and specific imaging target [11]. Furthermore, tracers targeting CD19 will enable visualization of B cells that escape CD20 therapy, and ultimately assist with patient stratification, dosing, and therapy monitoring.

Herein, we report the development and preclinical characterization of an antibody-based CD19 PET imaging agent. Our goal was to develop a new PET tracer to test the hypothesis that $\mathrm{CD} 19^{+} \mathrm{B}$ cells can be detected in the CNS and periphery of EAE mice.

\section{Methods \\ Animals}

All experiments involving animals were completed in accordance with the Stanford Administrative Panel on Laboratory Animal Care (APLAC), which is accredited by the Association for the Assessment and Accreditation of Laboratory Animal Care (AAALAC International). Female C57BL/6 J wild-type mice were purchased from Jackson Laboratories (11 weeks, Jax \#00664) and acclimatized for 1 week prior to experiments. Mice were housed in a temperature-controlled environment under a 12-h light/dark schedule with unrestricted access to food/water.

\section{EAE induction}

Mice were induced with EAE (Fig. 1) using kits from Hooke Laboratories Inc. (cat\# EK2160; Lawrence, MA). After anesthetizing mice with isoflurane gas (2.0-3.0\% for induction and $1.5-2.5 \%$ for maintenance), they were inoculated with myelin oligodendrocyte glycoprotein $\left(\mathrm{MOG}_{1-125}\right)$ in complete Freund's adjuvant (CFA) $(0.2$ $\mathrm{mL}$ per mouse, S.C.), followed by two pertussis toxin (PTX) injections (80-100 ng per injection, I.P., 2 and 24 $\mathrm{h}$ post-MOG injection, Supp. Fig. 1). All mice were weighed and scored daily in the morning from day 8 onwards according to standard EAE scoring systems: 0, no paralysis; 1 , loss of tail tone; 2 , hind limb weakness or 


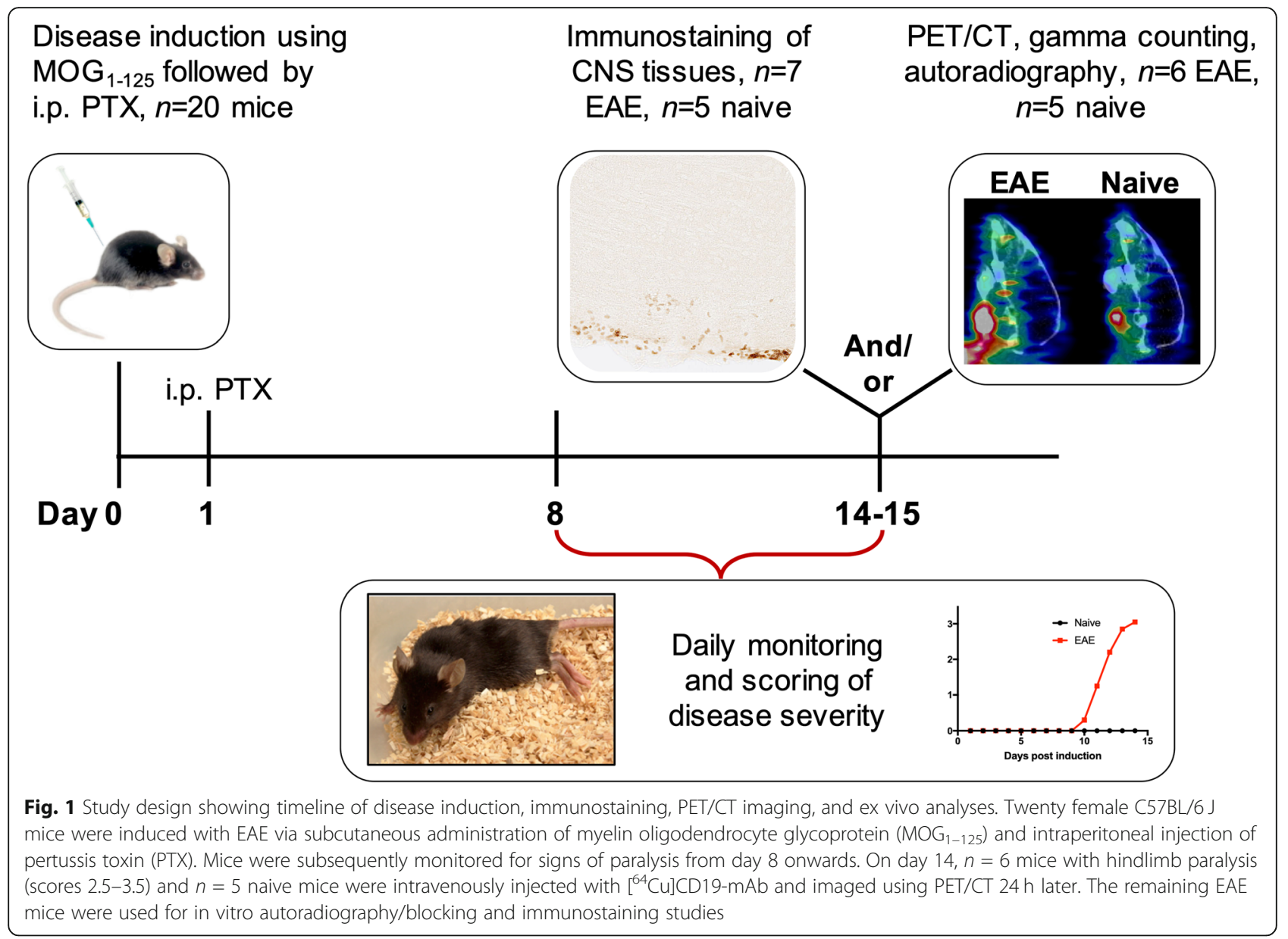

paresis; 3, hind limb paralysis; 4, complete hind leg and partial front leg paralysis. EAE mice were given supplemental food and fluids as necessary.

\section{Immunostaining}

Anti-CD45R (B220) immunostaining of brain tissue from $n=7 \mathrm{EAE}$ (of which $n=3$ mice had not been previously imaged using $\left.\left[{ }^{64} \mathrm{Cu}\right] \mathrm{CD} 19-\mathrm{mAb}\right)$ and $n=5$ naïve mice was carried out to investigate the load and location of CNS-infiltrating B cells. Following perfusion with 30 $\mathrm{mL}$ of phosphate-buffered saline (PBS), each brain was dissected, and the right hemisphere was fixed for $24 \mathrm{~h}$ in $4 \%$ paraformaldehyde (PFA) phosphate buffer and stored in $30 \%$ sucrose in PBS prior to sectioning at $40 \mu \mathrm{m}$ (Microm HM 450 sliding microtome; Thermo Scientific). Immunostaining of free-floating brain sections was performed using standard procedures [8]. Briefly, sections were thoroughly washed in tris-buffered saline (TBS) and pretreated with $0.6 \% \mathrm{H} 2 \mathrm{O} 2$ in $0.3 \%$ TritonXTBS prior to overnight $4{ }^{\circ} \mathrm{C}$ incubation with $1: 500$ biotinylated anti-B220/CD45R antibody (BD Pharmigen) in $0.3 \%$ Triton X-TBS. The following day, tissues were incubated for $1 \mathrm{~h}$ with the Vectastain Elite ABC kit (Vector
Laboratories) then exposed to $0.05 \%$ 3,3-diaminobenzidine (Sigma) in $0.1 \mathrm{MTrisCl}$ ( $\mathrm{pH} 7.4$ ) with $0.03 \% \mathrm{H} 2 \mathrm{O} 2$ for 3-4 min. Lastly, sections were washed in $0.1 \mathrm{M}$ TrisHCl prior to coverslipping.

\section{DOTA conjugation}

Mouse CD19 monoclonal antibody (CD19-mAb) (115502, clone 6D5, Biolegend; San Diego, CA) was conjugated with DOTA-NHS (Macrocyclics; Plano, TX) using metal-free buffers and previously published procedures [12]. Average number of chelator molecules per antibody was determined to be $2-3$ using electrospray ionization mass spectrometry (ESI-MS) and matrixassisted laser desorption/ionization-time of flight (MALDI-TOF).

\section{$\left[{ }^{64} \mathrm{Cu}\right]$-radiolabeling}

Radiolabeling of DOTA-CD19-mAb (Suppl. Fig. 1) was performed by modifying previously reported general copper labeling methods $[8,13]$. Briefly, immunoconjugate $(80 \pm 11 \mu \mathrm{g}, n=4)$ in $\mathrm{NH}_{4} \mathrm{OAc}(\mathrm{pH} 5.5)$ was added to $\left[{ }^{64} \mathrm{Cu}\right] \mathrm{CuCl}_{2}(0.06 \mathrm{GBq})$ in $\mathrm{NH}_{4} \mathrm{OAc}$ under gentle agitation at $37^{\circ} \mathrm{C}$ (final volume $100 \mu \mathrm{L}$ ) and the reaction 
monitored via radioTLC until a labeling efficiency of $>99 \%$ was observed $(15-30 \mathrm{~min})$. Thereafter, EDTA $(50 \mathrm{mM})$ was added $(2 \mu \mathrm{L})$. Reactions were analyzed by radioTLC (iTLC-SG glass microfibre strips developed in $50 \mathrm{mM}$ EDTA solution for $3 \mathrm{~min}$ ) and SECHPLC (size-exclusion HPLC, Phenomenex 00H-2146K0, $5 \mu \mathrm{m}$ SEC-s3000 $400 \AA, 300 \times 7.8 \mathrm{~mm}$ ). Pure fractions (> 99\%) of $\left[{ }^{64} \mathrm{Cu}\right] \mathrm{CD} 19-\mathrm{mAb}$ were combined and diluted with saline. Prior to in vivo studies, in vitro autoradiography was performed to assess specificity of $\left[{ }^{64} \mathrm{Cu}\right] \mathrm{CD} 19-\mathrm{mAb}$ using mouse spleen and brain tissue (Suppl. Fig. 2).

\section{In vivo $\mathrm{PET} / \mathrm{CT}$ acquisition}

On day 13 after EAE induction, mice were imaged using a dual microPET/computed tomography (CT) scanner (Inveon, Siemens). Mice ( $n=6 \mathrm{EAE}$, clinical score $\geq 3, n$ $=5$ naïve) were anesthetized with isoflurane gas and intravenously injected with $\left[{ }^{64} \mathrm{Cu}\right] \mathrm{CD} 19-\mathrm{mAb}$ (4.85$6.88 \mathrm{MBq}$, equivalent to 6.47-9.30 $\mu \mathrm{g}$ immunoconjugate). CT images were acquired as previously described [13] for anatomical reference prior to a 10 min static PET acquisition $21-24 \mathrm{~h}$ post tracer administration. On each imaging day, a calibration factor was calculated using a $20 \mathrm{~mL}$ syringe containing a known amount of radioactive $\left[{ }^{64} \mathrm{Cu}\right]$. PET data was acquired and reconstructed using previously described methods [8].

\section{PET analysis and quantitation}

CT and PET files were co-registered and analyzed using the VivoQuant 4 (inviCRO) and Inveon Research
Workspace 2.5 (Siemens) software to quantify tracer uptake in specific regions and to generate images, respectively. Brain regions of interest (ROIs) were chosen on the basis of our immunohistochemistry staining results (Fig. 2), as well as previous reports of tertiary lymphoid organs in brainstem and meninges of EAE mice [14]. For brain region quantitation, a 3D mouse brain atlas with ROIs for medulla, pons, and white matter was fitted to the PET/CT images via alignment of the atlas with the skull of each mouse (as determined by CT). Quantification of PET signal in all 15 brain regions that are part of the atlas are shown in Suppl. Fig. 3A. PET signal in the femur was quantified to assess levels of $\mathrm{CD} 19^{+} \mathrm{B}$ cells in bone marrow, whereby signal from bone was identified using Otsu thresholding following our previously published procedures [13], after which manual ROIs were drawn for bone marrow. Values were displayed as percentage of injected dose per gram (\%ID/g), allowing comparison with gamma counting results.

\section{Gamma counting and autoradiography}

Tissues were collected for gamma counting and autoradiography $24 \mathrm{~h}$ after injection of $\left[{ }^{64} \mathrm{Cu}\right] \mathrm{CD} 19-\mathrm{mAb}$ as previously described [8]. Tissues were collected for both in vitro. Briefly, 200-300 $\mu \mathrm{L}$ of blood was collected from the left cardiac ventricle of anesthetized mice prior to perfusion with $30-40 \mathrm{~mL}$ of PBS. Left brain hemisphere, heart, liver, spleen, cervical/thoracic (C/TSC), and lumbar (LSC) spinal cord were harvested, weighed, and counted using an automatic gamma counter (Hidex Oy, Helsinki, Finland), allowing \%ID/g to be calculated for

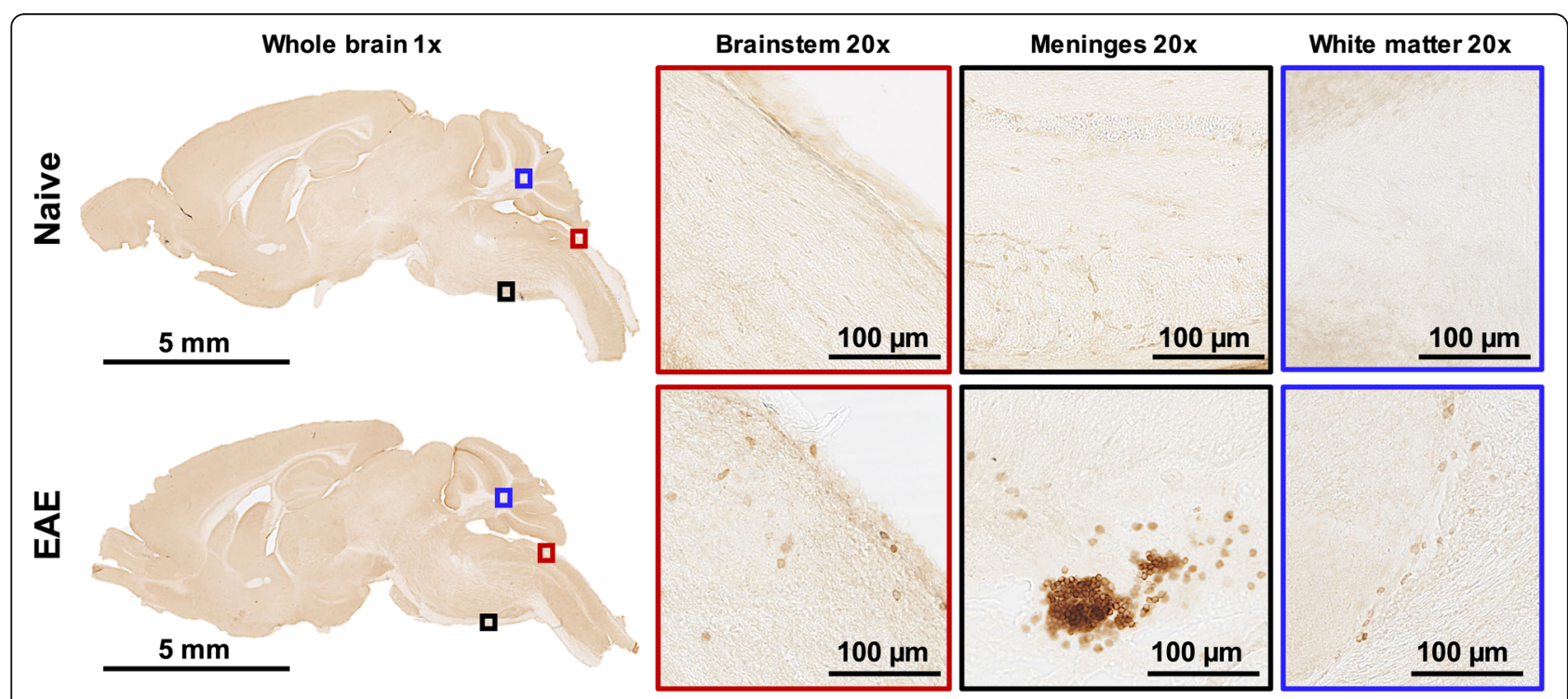

Fig. 2 B cell infiltrates are present in brainstem, meninges, and white matter of EAE mice. Representative B220 immunostaining of naïve and EAE mouse brain tissue ( $n=7 \mathrm{EAE}, n=5$ naïve mice, average of 4 slices per animal). Scale bars are $5 \mathrm{~mm}$ in low magnification ( $\times 1$ ) sagittal brain images and $100 \mu \mathrm{m}$ in high magnification $(\times 20)$ images of the brainstem, meninges, and cerebellar white matter 
each organ of interest. Autoradiography was performed using $40 \mu \mathrm{m}$-thick left-brain hemisphere sections and whole C/TSC and LSC to obtain high-resolution images of tracer distribution in CNS tissues, expressed as mean pixel intensity/decay-corrected dose (MPI/dose). Brain section anatomy was confirmed by Nissl staining of the same sections as previously described [15]. Autoradiography ROIs ( $n=4$ per group) were drawn on the basis of immunohistochemical findings and were defined as hindbrain (brainstem and cerebellum) and cerebellar white matter (Suppl. Fig. 3B).

\section{Statistics}

Statistical analyses were performed using Prism 7 (GraphPad). Data are represented as mean \pm SEM with individual values plotted on bar graphs. Shapiro-Wilk normality tests were conducted prior to unpaired Student's $t$ tests for PET, ex vivo tissue gamma counting (brain, blood, femur, spleen), and ex vivo autoradiography data. Two-way ANOVA with Šídák's multiplecomparisons post hoc tests were used for ex vivo gamma counting of vertebrae and spinal cord tissues. Pearson's correlation was used for IHC, autoradiography, and PET correlations. A $p$ value of less than 0.05 was considered statistically significant.

\section{Results}

\section{Disease induction}

EAE was induced by subcutaneous injection of $\mathrm{MOG}_{1-125}$ in female C57BL/6 J mice to evaluate the utility of $\left[{ }^{64} \mathrm{Cu}\right] \mathrm{CD} 19-\mathrm{mAb}$ for in vivo detection of B cells in a murine model of MS. Peak disease severity (clinical score $>3$ ) was observed within 12-14 days, with clinical scores ranging from 3 to 3.5 reflecting hindlimb paralysis (Fig. 1).

\section{Mouse model/immunohistochemistry}

To verify $B$ cell infiltration into the CNS of immunized mice, B220 immunostaining of brain tissue from $n=5$ naïve and $n=9$ EAE mice was performed (Fig. 2). Immunohistochemistry revealed increased $\mathrm{B}^{2} 20^{+}$cell numbers in the cerebellar white matter and associated meninges $\left(2.46 \pm 0.369\right.$ vs. $0.409 \pm 0.138$ cells $/ \mathrm{mm}^{2}, * * p$ $=0.00210)$, as well as in brainstem and associated meninges $\left(5.42 \pm 1.65\right.$ vs. $0.199 \pm 0.0980$ cells $/ \mathrm{mm}^{2},{ }^{*} p=$ 0.0390), particularly in the subarachnoid space, of EAE compared to naïve mice. $B$ cells were found in dense clusters similar to follicle-like structures observed in the meninges of MS patients, with a highly heterogeneous spatial distribution [16].

\section{Synthesis and characterization of $\left[{ }^{64} \mathrm{Cu}\right] \mathrm{CD} 19-\mathrm{mAb}$}

An average conjugation of 3 DOTA per CD19-mAb was achieved and subsequent radiolabeling with ${ }^{64} \mathrm{Cu}$ yielded
$>99 \%$ radiochemical purity and a molar activity of 2.2 GBq $/ \mu$ mol ( $n=14$ reactions, Suppl Fig. 4, Suppl Fig. 5). Specificity of $\left[{ }^{64} \mathrm{Cu}\right] \mathrm{CD} 19-\mathrm{mAb}$ was evaluated in vitro, whereby blocking results showed significantly decreased tracer binding in naïve spleen and EAE brain tissue that was pre-incubated with 1000-fold mass dose of unlabeled unconjugated mAb (Suppl. Fig. 2).

\section{PET/CT imaging}

To investigate the ability of $\left[{ }^{64} \mathrm{Cu}\right] \mathrm{CD} 19-\mathrm{mAb}$ to detect $\mathrm{CD} 19^{+} \mathrm{B}$ cells in immunized mice, in vivo PET images were acquired and quantified in regions implicated in EAE pathology (medulla, pons, white matter, and whole brain) for $n=6 \mathrm{EAE}$ and $n=5$ naïve mice (Fig. 3a). PET quantitation of white matter $(1.72 \pm 0.0950$ vs. $1.18 \pm$ $\left.0.0590 \% \mathrm{ID} / \mathrm{g},{ }^{* * *} p=0.00140\right)$ and whole brain $(2.02 \pm$ 0.0920 vs. $\left.1.68 \pm 0.0600 \% \mathrm{ID} / \mathrm{g},{ }^{*} p=0.0173\right)$ showed significant increases in tracer uptake for EAE compared to naïve mice (Fig. 3b). This pattern was also observed between EAE and naïve mice in the pons $(2.52 \pm 0.183$ vs. $\left.1.78 \pm 0.220 \% \mathrm{ID} / \mathrm{g},{ }^{*} p=0.0270\right)$ and medulla $(2.54 \pm$ 0.123 vs. $2.08 \pm 0.135 \% \mathrm{ID} / \mathrm{g}$, ${ }^{*} p=0.0310$, Fig. $\left.3 \mathrm{~b}\right)$. Conversely, tracer uptake in femur showed reduced binding of $\left[{ }^{64} \mathrm{Cu}\right] \mathrm{CD} 19-\mathrm{mAb}$ in bone marrow of EAE compared to naïve mice $(4.18 \pm 0.366$ vs. $6.76 \pm 0.957 \% \mathrm{ID} / \mathrm{g}$, " $p=$ 0.0242, Suppl. Fig. 6).

\section{Ex vivo biodistribution and autoradiography}

To compare tracer uptake in tissues of EAE and naïve mice without the contribution of tracer in the blood pool, ex vivo gamma counting was performed after perfusion using half brains, cervical/thoracic spinal cord, lumbar spinal cord, blood (from cardiac puncture prior to perfusion), femur, heart, liver, muscle, spleen, cervical/thoracic vertebrae, and lumbar vertebrae (Fig. 4 and Suppl. Fig. 7). In the CNS (Fig. 4a), tracer uptake was significantly elevated in the brain $(0.220 \pm 0.0200$ vs. 0.120 $\pm 0.00300 \% \mathrm{ID} / \mathrm{g}, p=0.001)$ and cervical/thoracic spinal cord $(0.571 \pm 0.104$ vs. $0.122 \pm 0.0180 \% \mathrm{ID} / \mathrm{g}, p=0.0375$ of EAE compared to naïve mice, with a trend in the lumbar spinal cord $(0.750 \pm 0.186$ vs. $0.350 \pm 0.0780 \% \mathrm{ID} / \mathrm{g}, p$ $=0.0661$ ). Separating the vertebrae from spinal cord tissue revealed a significant decrease in tracer uptake in the lumbar vertebrae $(2.73 \pm 0.188$ vs. $4.42 \pm 0.429 \% \mathrm{ID} / \mathrm{g}, p=$ $0.0007)$, but not in the cervical/thoracic vertebrae (2.26 \pm 0.198 vs. $3.02 \pm 0.262 \% \mathrm{ID} / \mathrm{g}, p=0.121$ ) between EAE and naive mice. EAE mice exhibited significantly lower tracer uptake in femur $(4.07 \pm 0.450$ vs. $9.71 \pm 0.717 \% \mathrm{ID} / \mathrm{g}, p<$ $0.0001)$ and spleen $(132 \pm 9.31$ vs. $265 \pm 32.7 \% \mathrm{ID} / \mathrm{g}, p=$ 0.002) compared to naive mice (Fig. $4 \mathrm{~b}$ ). However, there were no significant differences in tracer uptake in the muscle $(1.52 \pm 0.18$ vs. $1.09 \pm 0.04 \% \mathrm{ID} / \mathrm{g}, p=0.0650)$, liver $(10.2 \pm 1.16$ vs. $8.08 \pm 0.56 \% \mathrm{ID} / \mathrm{g}, p=0.15)$, or heart 


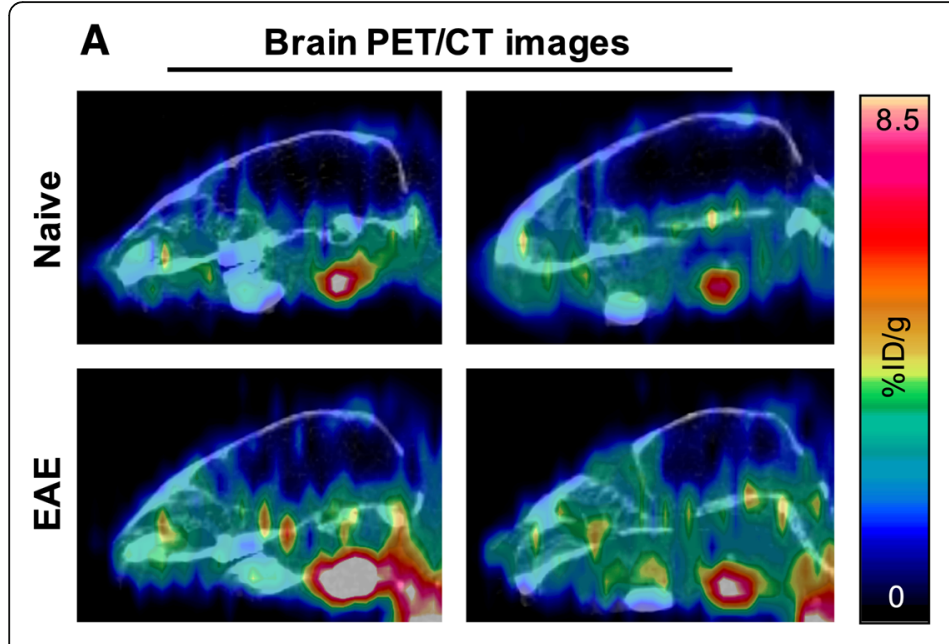

B

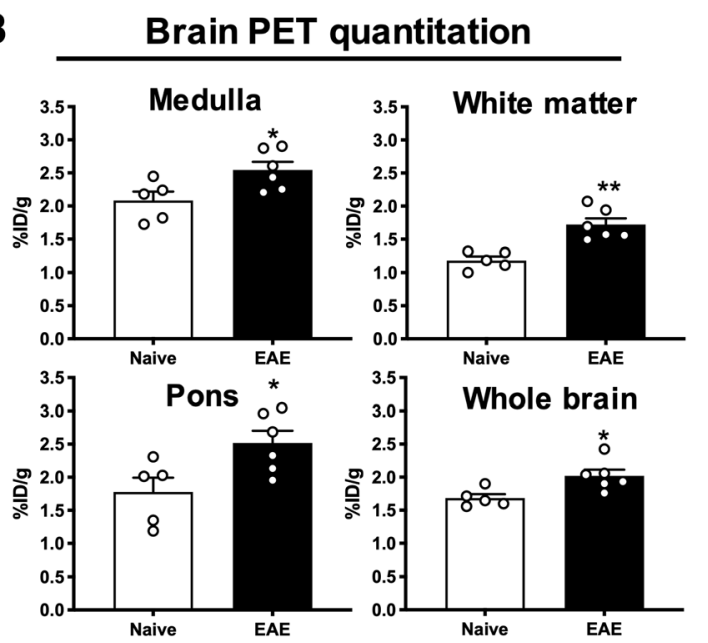

Fig. 3 CD19-PET imaging shows increased signal in the brain of EAE mice. a Representative sagittal brain PET/CT images of naïve and EAE mice $24 \mathrm{~h}$ after $\left[{ }^{64} \mathrm{Cu}\right] \mathrm{CD} 19-\mathrm{mAb}$ injection. $\mathbf{b}$ Quantitation of tracer binding in medulla, pons, white matter, and whole brain, $n=5$ per group. ${ }^{*} p=<$ $0.05,{ }^{* *} p=<0.01$

$(1.71 \pm 0.16$ vs. $1.38 \pm 0.204 \% \mathrm{ID} / \mathrm{g}, p=0.240)$ between EAE and naïve mice (Suppl. Fig. 7).

Brain and spinal cord tissues were further evaluated using ex vivo autoradiography to determine the spatial distribution of tracer uptake in the CNS with higher resolution (Fig. 5 and Suppl. Fig 3B). Quantitation revealed significantly increased tracer uptake in the brainstem $(107.7 \pm 6.291$ vs. $56.44 \pm 1.532 \mathrm{MPI} /$ dose, $p=0.0002)$, cerebellar white matter $(78.2 \pm 11.6$ vs. $43.7 \pm 3.37 \mathrm{MPI} /$ dose, $p=0.0290)$, whole cerebellum (73.2 \pm 7.44 vs. $45.7 \pm$ $3.03 \mathrm{MPI} /$ dose, $p=0.0172)$, cervical/thoracic spinal cord
(165 \pm 21.6 vs. $55 \pm 5.06 \mathrm{MPI} /$ dose, $p=0.0011)$, and lumbar spinal cord $(155 \pm 24.9$ vs. $65.3 \pm 6.39 \mathrm{MPI} /$ dose, $p=$ $0.0060)$ of $n=4$ EAE compared to $n=4$ naïve representative mice (Fig. 5c and Suppl. Fig. 3B).

Correlation between immunohistochemistry and imaging findings

To better understand how $\left[{ }^{64} \mathrm{Cu}\right] \mathrm{CD} 19-\mathrm{mAb}$ tracer signal relates to levels of $\mathrm{B}$ cells in individual mice, we investigated the correlation between B220 immunohistochemistry, autoradiography, and PET quantitation. Results

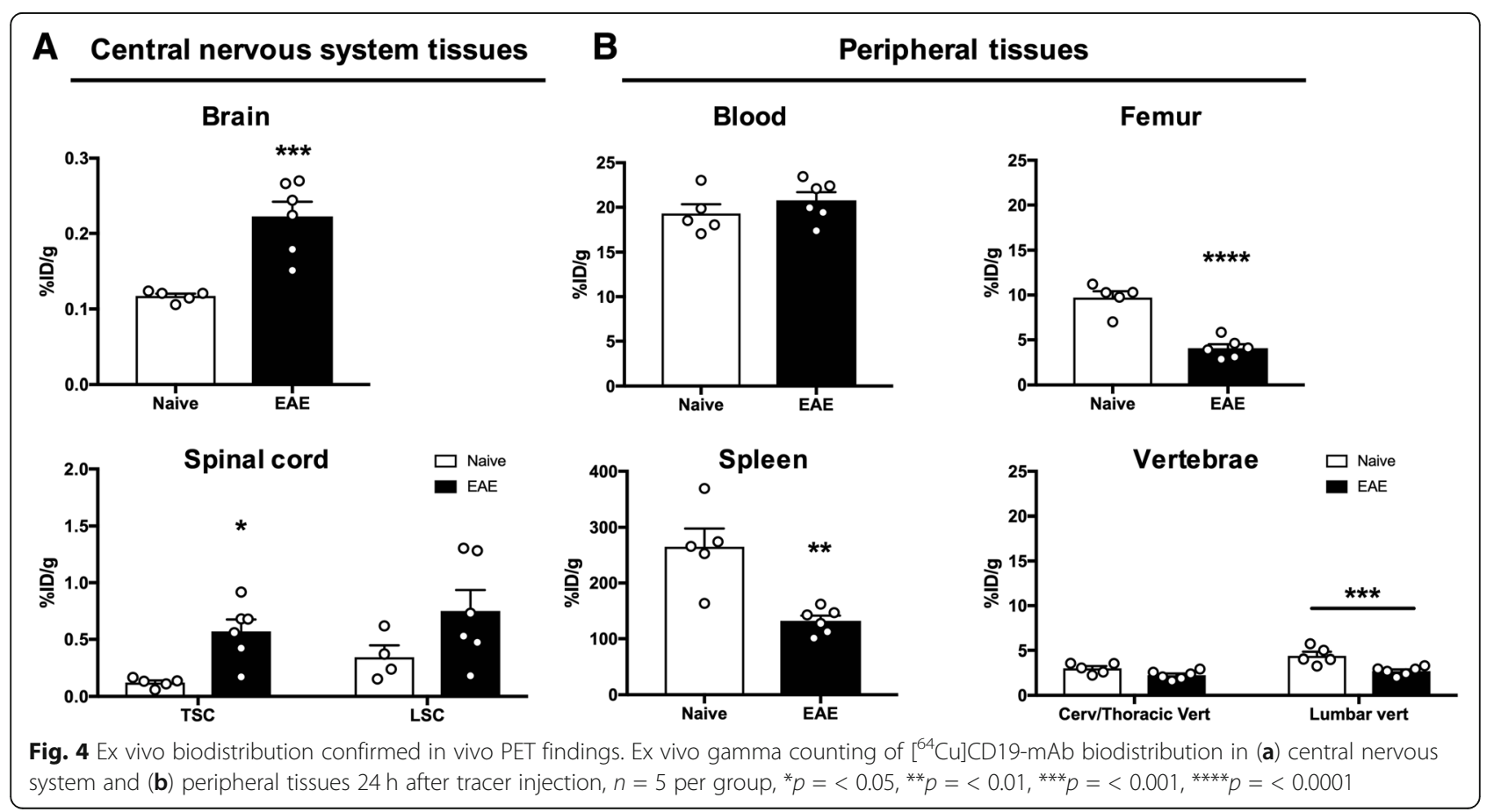




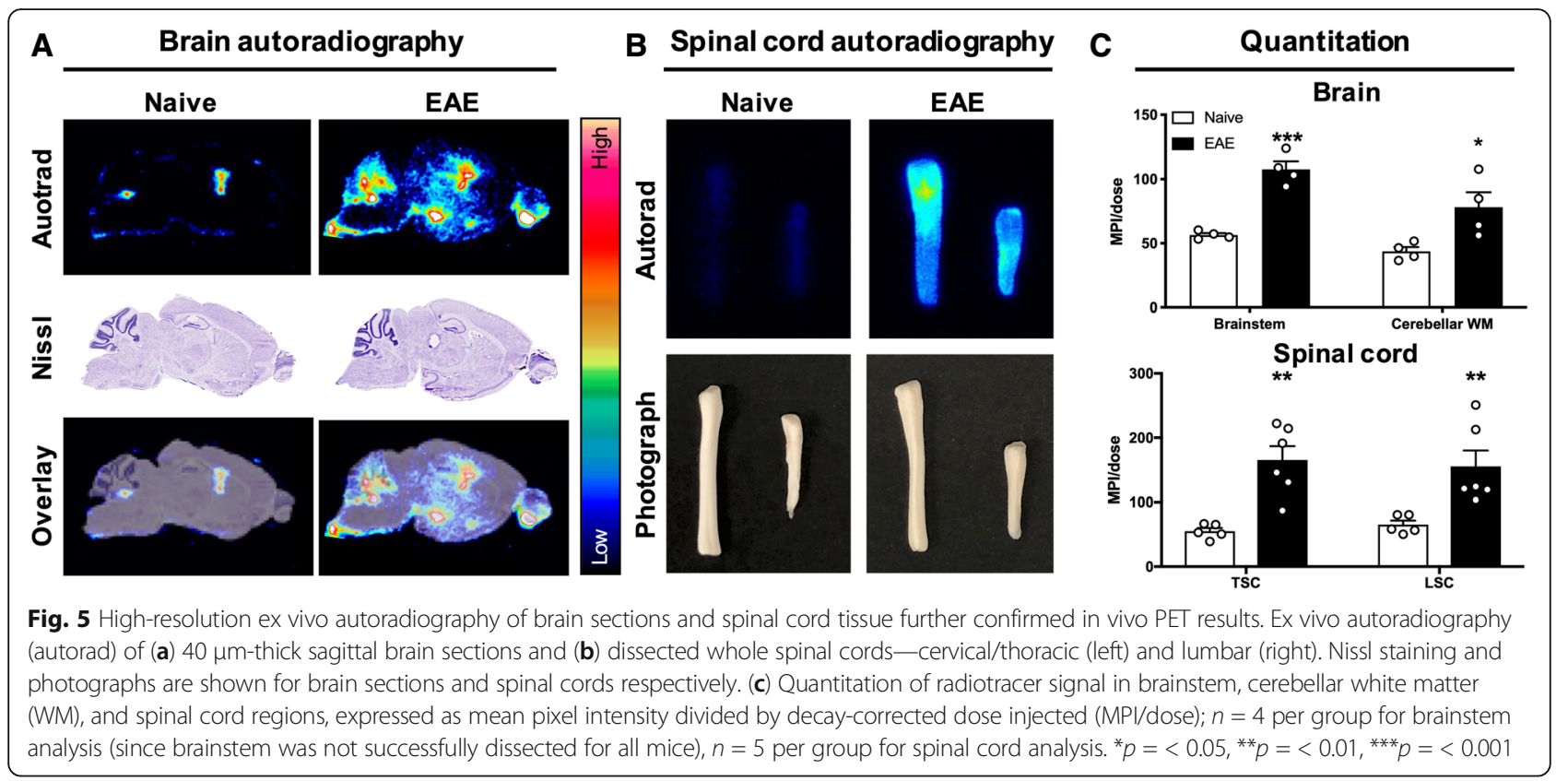

depicted in Fig. 6a illustrate a significant positive correlation between in vivo PET and ex vivo autoradiography of $\left[{ }^{64} \mathrm{Cu}\right] \mathrm{CD} 19-\mathrm{mAb}$ in cerebellar white matter, $(r=0.735, * p=0.0378)$ and hindbrain (brainstem and cerebellum) $(r=0.947, * p=$ 0.00410). Correlation between autoradiography and
B220 staining in the cerebellar white matter revealed a lack of correspondence between ex vivo imaging and B cell counts $(r=0.485, p=0.223$, Fig. 6c), whereas hindbrain autoradiography showed a trending positive correlation with $\mathrm{B}$ cell numbers $(r=$ 0.784, $p=0.0650$, Fig. $6 \mathrm{~d}$ ).
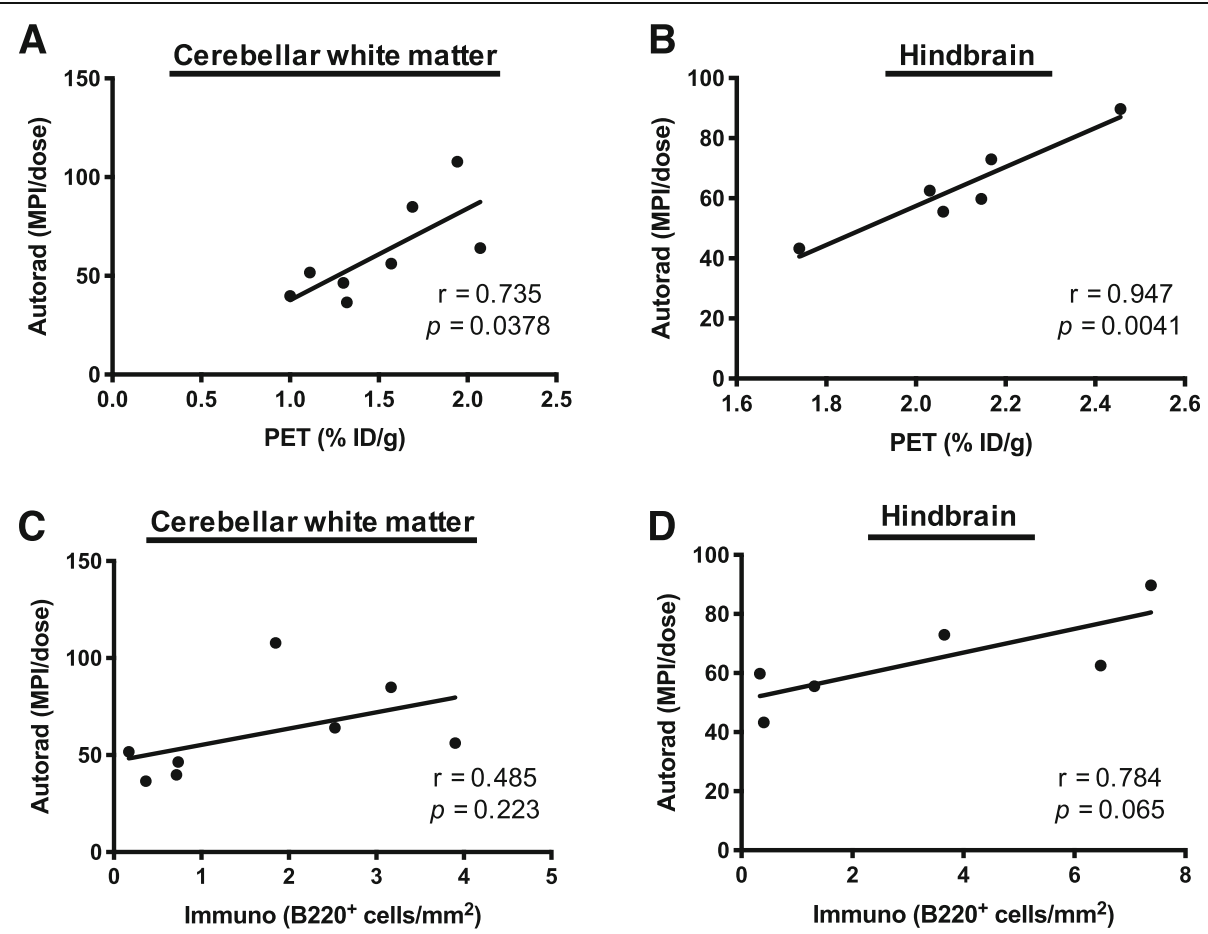

Fig. 6 Ex vivo autoradiography correlates with PET or B220 immunohistochemistry. Correlation between ex vivo autoradiography and PET or B220 immunohistochemistry of (A/C) cerebellar white matter and (B/D) cerebellum + brainstem (i.e., hindbrain), naïve, and EAE mice ( $n=3-4$ per group) 


\section{Discussion}

In this study, we sought to generate a PET tracer specific for CD19-positive B cells to enable detection of a broad range of $B$ cell subsets in vivo, including pro B cells, plasmablasts, and early plasma cells. We successfully synthesized a ${ }^{64} \mathrm{Cu}$-labeled mAb targeting CD19 and demonstrated its utility for visualizing $\mathrm{B}$ cell distribution in EAE mice with high sensitivity, in both the CNS and peripheral tissues.

The selected EAE model using full-length $\mathrm{MOG}_{1-125}$ protein was well-suited for this work due to its ability to induce B cell immune responses [17]. In this EAE model, a sub-population of antigen-activated B cells differentiate into plasma cells, resulting in the production of autoantibodies against MOG. Anti-MOG autoantibodies produced by $\mathrm{B}$ cells result in CNS inflammation and subsequent demyelination [17-19]. Moreover, previous reports have shown that induction of EAE using $\mathrm{MOG}_{1-}$ 125 in mice leads to B cell infiltration into the spinal cord and brain [8]. Indeed, our B220 immunostaining confirmed the existence of follicle-like structures containing dense $\mathrm{B}$ cell aggregates in the meninges, in addition to $\mathrm{B}$ cell infiltration in the brainstem and cerebellar white matter, of EAE mice, compared to negligible levels of $\mathrm{B}$ cells in naïve mouse brain tissue (Suppl. Fig. 8). These results are in agreement with investigations of MS lesions from treatment-naïve patients showing $\mathrm{CD}^{+} \mathrm{O}^{+} \mathrm{B}$ cell infiltration in all disease stages [20]. In addition to the presence of B cells in MS CNS lesions, they often form follicle-like clusters in extra-parenchymal regions, including the subarachnoid space within the meninges [21], which we also observed in our diseased mice. The contribution of demyelination to EAE pathogenicity has been previously demonstrated by $\mathrm{Al}$-Ani and coworkers, who showed a positive immunohistochemical correlation between $\mathrm{B}$ cell infiltration in the spinal cord with demyelination markers [22]. Although the chief focus of the current study was to validate the in vivo binding properties of our PET tracer, future studies will involve investigating the relationship between demyelination markers and CD19-PET.

Prior to initiating in vivo studies, we first verified the specificity of our CD19 PET tracer by performing in vitro autoradiography both with and without preblocking using excess CD19-mAb. The marked decrease in autoradiography signal in brain and spleen tissue from EAE mice after blocking confirmed specific binding of $\left[{ }^{64} \mathrm{Cu}\right] \mathrm{CD} 19-\mathrm{mAb}$ to $\mathrm{CD} 19^{+}$cells and warranted its further use and evaluation. Subsequently, in vivo PET findings revealed increased signal in the brainstem and white matter of EAE mice, mirroring the spatial distribution observed in B220 immunohistochemical staining of brain tissue from the same cohort of mice. It is important to note that while the contribution of blood signal (i.e., tracer residing in blood pool) increases the observed $\% \mathrm{ID} / \mathrm{g}$ for in vivo brain $\mathrm{PET}$ imaging, these results were corroborated by quantitative ex vivo gamma counting following perfusion, in which significantly increased signal was observed in whole brain of EAE mice (after the removal of blood). Additionally, high-resolution autoradiography enabled detailed analysis of the location of PET tracer binding in CNS tissues, and matched the distribution pattern of $\mathrm{B}^{2} 2 \mathrm{O}^{+}$cells observed by brain immunohistochemistry. Autoradiography was especially useful for verifying $\left[{ }^{64} \mathrm{Cu}\right] \mathrm{CD} 19-\mathrm{mAb}$ binding in the white matter which is difficult to discern using PET alone due to the limited spatial resolution of small animal PET. Similarly, autoradiography was used to demonstrate elevated tracer binding in spinal cord tissue from EAE mice compared to that observed in naïve mice. Unfortunately, the limited spatial resolution of small animal PET imaging and issues regarding the partial volume effect makes it difficult to delineate in vivo tracer binding to CD19+ cells in the spinal cord versus tracer binding to CD19+ cells in the bone marrow of the vertebral column (which are two relatively small structures in close proximity). Therefore, in vivo mouse PET images obtained during this study do not allow an accurate visualization of $B$ cells in spinal cord, due to signal spillover from the vertebral bone marrow into the spinal cord and vice versa. Importantly, this will not be an issue in the clinical setting since these structures are significantly larger in humans.

Tracer binding was also quantified in tissues outside the CNS via PET imaging and ex vivo gamma counting. Visually, we observed higher PET signal in lymph nodes of EAE mice compared to naives (Suppl. Fig. 9). For bone marrow, the pattern of binding was the reverse of what was observed in lymph nodes and in the CNS-i.e., a dramatic reduction in signal in both femur and lumbar vertebrae from EAE compared to naïve mice. This may be due to trafficking of B cells out of repositories such as bone marrow in tandem with disease progression. Similarly, gamma counting of spleens revealed an almost $50 \%$ reduction in signal from EAE animals, reflecting a possible egress of $\mathrm{B}$ cells during the diseased state. A previously reported longitudinal flow cytometric analysis of EAE mouse tissues [23] shows that both $\mathrm{T}$ and $\mathrm{B}$ cells traffic from the spleen to the lymph nodes where they become activated, proliferate, and subsequently travel through the circulation to the CNS. This phenomenon may also occur in MS patients. In fact, the commonly prescribed MS therapeutic, fingolimod, exerts much of its beneficial effects by reducing the egress of lymphocytes out of secondary lymphoid tissues, decreasing numbers of $\mathrm{T}$ and $\mathrm{B}$ cells in circulation [24]. Although outside the scope of the current study, a method to track live cells emanating from the bone marrow lineage 
following adoptive transfer in EAE mice will be valuable. A recent study by Ortega and coworkers [25] used B cells labeled with a fluorophore in a stroke model, allowing tracking from the periphery into the CNS. Our future investigations will employ a similar approach, wherein mice lacking lymphocytes will be seeded with $B$ cells and induced with EAE prior to sequential imaging, allowing monitoring of $\mathrm{B}$ cell reservoirs and their involvement in CNS pathogenicity via longitudinal PET imaging.

Finally, we sought to investigate the relationship between observed in vivo and ex vivo tracer signal and underlying B cell load, as well as the association between in vivo and ex vivo imaging data. A strong positive correlation was observed between in vivo PET and ex vivo autoradiography in the hindbrain, providing further evidence of tracer specificity. A positive trend could also be seen between autoradiography of the hindbrain and increasing B cell count, reflective of the disease state. However, this trend was only weakly discernible when individual brain regions were investigated, possibly due to heterogeneous spatial distribution of B cell clusters across the brain similar to that observed in the clinical setting. This approach is potentially limited by the use of opposing brain hemispheres for immunohistochemistry and autoradiography. This could be mitigated by using adjacent sections for the separate techniques, with the possible risk of compromised tissue quality for B220 staining. Additionally, the expression of B220 (CD45R), a pan-B cell marker in mice, does not overlap fully with that of CD19, and cells negative for either surface marker would be excluded from this analysis.

\section{Conclusion}

Overall, the results from the current work provide strong evidence that a tracer targeting CD19 can detect $B$ cells in the CNS and periphery of a mouse model of MS. The increasing focus on B cells as therapeutic targets in neurodegenerative diseases such as MS, and more recently NMO [7], highlights the need for methodology that will allow treatment monitoring and patient selection for anti-B cell clinical trials. The tools developed as part of this work have the potential to inform future preclinical research by providing a new tool to visualize B cells in the context of different diseases. Our future studies will focus on evaluating this CD19 PET tracer in mouse models of other neurological and neuromuscular diseases involving B cells, including stroke [26], NMO [27], and myasthenia gravis [28], in addition to lymphoma. We will also investigate the use of ${ }^{89} \mathrm{Zr}$-labeled CD19 mAbs, allowing imaging at later timepoints with a reduced contribution from the blood pool. Although the investigation of individual subsets of CD19+ $B$ cell populations and their pathogenic effects was outside of the scope of this investigation, we acknowledge the importance of understanding which B cell subsets contribute to the observed PET signal in different parts of the body and CNS in the context of health and disease, and therefore this will also be part of additional planned studies.

\section{Supplementary information}

Supplementary information accompanies this paper at https://doi.org/10. 1186/s12974-020-01880-8.

Additional file 1: Suppl. Fig 1. Generation of the first reported PET tracer for CD19+ B cells via DOTA-conjugation of a CD19-specific mAb and subsequent radiolabeling with copper-64 $\left(\left[{ }^{64} \mathrm{Cu}\right]\right)$. Suppl. Fig. 2. In vitro autoradiography of $\left[{ }^{64} \mathrm{Cu}\right] \mathrm{CD} 19-\mathrm{mAb}$ and anatomical staining of spleen and brain tissue sections. Frozen tissue sections were allowed to reach ambient temperature, after which they were washed in $50 \mathrm{mM}$ Tris- $\mathrm{HCl}$ for $3 \times 5$ min at $\mathrm{pH} 7.4$, before drying under airflow for 30 min. A perimeter was drawn around the tissue with a hydrophobic pen and blocking antibody (1000x based on specific activity calculated by spectrophotometry) was added to half of the slides, followed by incubation for $30 \mathrm{~min}$ at ambient temperature. After washing off the blocking slides ( $3 \times 2$ min Tris- $\mathrm{HCl}, 50 \mathrm{mM}, \mathrm{pH}$ 7.4), a solution containing

$\left[{ }^{64} \mathrm{Cu}\right] \mathrm{CD} 19-\mathrm{mAb}$ tracer $(500 \mu \mathrm{L}, 2.5 \mu \mathrm{Ci} / \mathrm{mL})$ was carefully applied using a pipette and slides were left to incubate for $30 \mathrm{~min}$, before $3 \times 2 \mathrm{~min}$ washes in Tris- $\mathrm{HCl}$ ( $50 \mathrm{mM}, \mathrm{pH} 7.4$, ambient temperature). Finally, all slides were dipped twice into ice water and left to dry for 30 min under airflow. Slides were transferred to a phosphorimaging plate and stored at $-20{ }^{\circ} \mathrm{C}$ for 24 h, before development using a Typhoon laser scanner. Gel images were analyzed using ImageJ software. Fig. 3A. In vivo PET detects increased signal in distinct brain regions. $3 \mathrm{D}$ brain atlas tool from Invicro (Boston, MA) allows automated analysis of individual brain regions. Skull CT was used to define total brain volume for determination of activity. $n=5$ naïve, $n=6 E A E,{ }^{* *} p=.0082$, two-way ANOVA. Suppl. Fig. 3B. Uptake of $\left[{ }^{64} \mathrm{Cu}\right] \mathrm{CD} 19-\mathrm{mAb}$ corresponds to spatial distribution observed in immunohistochemistry. A. Ex vivo autoradiography, 50 $\mu \mathrm{m}$ resolution. B. Quantitation of uptake in cerebellum, $n=4$ naïve and $\mathrm{EAE},{ }^{*} p=.0286$, unpaired t-test. Coloured outlines denote ROls drawn in ImageJ. Suppl. Fig. 4A. Samples were analyzed by ESI-MS on an Agilent 1260 HPLC and Bruker MicroTOF-Q II, running a 12 min gradient of 5 to $95 \%$ 0.1\% formic acid in MeCN, solvent A was $0.1 \%$ formic acid in water. Panels $A$ and $C$ depict the TIC of unconjugated and immunoconjugate (2.9 DOTA) running in positive mode, $B$ and $D$ depict the deconvoluted mass spectra of the same compounds. The column was a Waters MassPREP $5 \times 2.1 \mathrm{~mm}$ diphenyl desalting column, the temperature was $50^{\circ} \mathrm{C}$, and the flow rate was $0.3 \mathrm{ml} / \mathrm{min}$. Injection volume was $15 \mu \mathrm{L}$. Suppl. Fig. 4B. Antibody samples underwent buffer exchange/desalting using Zip-Tip $\mathrm{C}_{18}$ filters, at a final concentration of approx. $1 \mathrm{mg} / \mathrm{mL}$ in $0.1 \%$ TFA/60\% MeCN/40\% $\mathrm{H}_{2} \mathrm{O}$. Each spot was loaded with approx. $1 \mu \mathrm{g}, 0.5$ pmol internal standard (BSA) was added and samples were analysed using an Applied Biosystems SCIEX 5800 TOF/TOF instrument with high mass detection. A. Unconjugated antibody. B. Immunoconjugate following addition of chelator. Suppl. Fig. 5. Antibody samples were analyzed by SEC-HPLC. A) UV (280 nm), unconjugated CD19 anti-mouse antibody, clone 6D5. B) UV (280 nm), immunoconjugate following DOTA chelation. C. Radiochromatogram of B. Suppl. Fig. 6. Femur PET/CT shows increased signal in naïve mice compared to EAE, likely due to CD19-positive B cells trafficking out of bone marrow in diseased mice. Bone was identified using Otsu thresholding and bone marrow ROls were drawn in manually. A) Representative PET/CT image from femur of naïve and EAE mice. (B) In vivo PET quantitation of PET image, $n=5$ naïve, $n=6 E A E,{ }^{* *} p=.0071$, unpaired t-test. Suppl. Fig. 7. Ex vivo gamma counting of $\left[{ }^{64} \mathrm{Cu}\right] \mathrm{CD} 19-\mathrm{mAb}$ biodistribution showing no significant differences between EAE and naive heart, liver, and muscle $24 \mathbf{~ h}$ after tracer injection. $n=5$ naïve, $n=6 \mathrm{EAE}^{* *} p=.0021$, ${ }_{* * * *}^{*}<<.0001$, unpaired t-test. Suppl. Fig. 8. Quantitative immunohistochemical quantitation of $\mathrm{B220}^{+}$cell load in cerebellum and brainstem $n=5$ naïve, $n=10 E A E,{ }^{*} p=.0195$ for cerebellum, ${ }^{*} p=.0417$ for 
brainstem, unpaired t-test. Brainstem was missing in one EAE mouse following tissue preparation and sectioning $(n=9)$. Suppl. Fig. 9. PET/CT images acquired $20 \mathrm{~h}$ post-injection, showing uptake of tracer in a) cervical lymph node, b) spleen, c) mesenteric lymph node and d) inguinal lymph node. Percentage of injected dose per gram $(\% \mathrm{ID} / \mathrm{g})$ scaled to allow comparison between different mice.

\section{Abbreviations}

AAALAC International: Association for the assessment and accreditation of laboratory animal care; APLAC: Administrative panel on laboratory animal care; Autorad: Autoradiography; CFA: Complete Freund's adjuvant; CNS: Central nervous system; CT: Computed tomography; C/TSC: Cervical/ thoracic spinal cord; EAE: Experimental autoimmune encephalomyelitis; ESIMS: Electrospray ionization mass spectrometry; i.p.: Intraperitoneal; i.v.: Intravenous; LSC: Lumbar spinal cord; mAb: Monoclonal antibody; MALDITOF: Matrix-assisted laser desorption/ionization-time of flight; MOG: Myelin oligodendrocyte glycoprotein; MPI/dose: Mean pixel intensity/decaycorrected dose; MRI: Magnetic resonance imaging; MS: Multiple sclerosis; NMO: Neuromyelitis optica; O.C.T.: Optimal cutting temperature; PBS: Phosphate buffered saline; PET: Positron emission tomography; PFA: Paraformaldehyde; PTX: Pertussis toxin; ROI: Region of interest; RRMS: Relapsing-remitting MS; TBS: Tris-buffered saline; WM: Cerebellar white matter; \%ID/g: Percentage of injected dose per gram

\section{Acknowledgements}

We thank Drs. Tim Doyle and Frezghi Habte of the Small Animal Imaging Facility at Stanford for assistance with PET/CT, Ms. Theresa McLaughlin of Stanford University Mass Spectrometry for assistance with ESI-MS, and Mr. Ken Lau of the Canary Center for assistance with MALDI-TOF.

\section{Authors' contributions}

MYS and HCC conceived and designed the research studies, developed the methodology, conducted experiments, acquired and analyzed the data, and prepared the manuscript. KLL conducted the experiments, acquired data, and reviewed the manuscript. AMC provided conceptual advice, conducted the experiments, and reviewed the manuscript. KL provided conceptual advice, analyzed data, and reviewed the manuscript. IMJ conducted the experiments and reviewed the manuscript. MB provided advice on the study design and interpretation of results, in addition to reviewing the manuscript. MLJ conceived and designed research studies, in addition to preparing the manuscript with MYS and HC. All authors read and approved the final manuscript.

\section{Funding}

This study was funded by the Stanford Wu Tsai Neurosciences Institute. MYS was funded by the Knut and Alice Wallenberg Foundation.

\section{Availability of data and materials}

The datasets during and/or analyzed during the current study will be made available from the corresponding author on reasonable request.

\section{Ethics approval and consent to participate}

Ethical approval was obtained for all animal studies detailed in this manuscript, and all applicable institutional guidelines for the care and use of animals were followed.

\section{Consent for publication}

Not applicable

\section{Competing interests}

The authors declare that they have no competing interests. MLJ received a speaker honorarium from Genentech and owns stock in Willow Neurosciences.

\section{Author details}

'Department of Radiology, Molecular Imaging Program at Stanford, 1201 Welch Rd, Stanford, CA 94305, USA. ²Department of Pathology, Stanford University, Stanford, CA, USA. ${ }^{3}$ Department of Neurology \& Neurological Sciences, Stanford University, Stanford, CA, USA.
Received: 20 March 2020 Accepted: 23 June 2020

Published online: 18 September 2020

\section{References}

1. Agius MA, Klodowska-Duda G, Maciejowski M, Potemkowski A, Li J, Patra K, Wesley J, Madani S, Barron G, Katz E, Flor A. Safety and Tolerability of Inebilizumab (MEDI-551), an Anti-CD19 Monoclonal Antibody, in Patients with Relapsing Forms of Multiple Sclerosis: Results from a Phase 1 Randomised, Placebo-Controlled, Escalating Intravenous and Subcutaneous Dose Study. Mult Scler J. 2017:1-11.

2. Al-ani MR, Raju TK, Hachim MY, Hachim IY, Elemam NM, Guimei M, Bendardaf R, Maghazachi AA. Rituximab Prevents the Development of Experimental Autoimmune Encephalomyelitis (EAE): Comparison with Prophylactic, Therapeutic or Combinational Regimens. J Inflamm Res. 2020; 13:151-64.

3. Barthelmes J, Tafferner N, Kurz J, de Bruin N, Parnham MJ, Geisslinger G, Schiffmann S. Induction of Experimental Autoimmune Encephalomyelitis in Mice and Evaluation of the Disease-Dependent Distribution of Immune Cells in Various Tissues. JoVE. 2016:e53933.

4. Challa DK, Bussmeyer U, Khan T, Montoyo HP, Bansal P, Ober RJ, Ward ES. Autoantibody Depletion Ameliorates Disease in Murine Experimental Autoimmune Encephalomyelitis. MAbs. 2013;5:655-9.

5. Chen D, Gallagher S, Monson NL, Herbst R, Wang Y. Inebilizumab, a B CellDepleting Anti-CD19 Antibody for the Treatment of Autoimmune Neurological Diseases: Insights from Preclinical Studies. J Clin Med. 2016;5: 107.

6. Cree BAC, Bennett JL, Kim HJ, Weinshenker BG, Pittock SJ, Wingerchuk DM, Fujihara K, Paul F, Cutter GR, Marignier R, Green AJ, Aktas O, Hartung H-P, Lublin FD, Drappa J, Barron G, Madani S, Ratchford JN, She D, Cimbora D, Katz E. Inebilizumab for the Treatment of Neuromyelitis Optica Spectrum Disorder (N-MOmentum): A Double-Blind, Randomised Placebo-Controlled Phase 2/3 Trial. Lancet. 2019.

7. Cropper HC, Johnson EM, Haight ES, Cordonnier SA, Chaney AM, Forman TE, Biswal A, Stevens MY, James ML, Tawfik VL. Longitudinal Translocator Protein-18 KDa-Positron Emission Tomography Imaging of Peripheral and Central Myeloid Cells in a Mouse Model of Complex Regional Pain Syndrome. Pain. 2019;160.

8. Cree, B.A.C.; Bennett, J.L.; Kim, H.J.; Weinshenker, B.G.; Pittock, S.J.; Wingerchuk, D.M.; Fujihara, K.; Paul, F.; Cutter, G.R.; Marignier, R.; Green, A.J. Aktas, O.; Hartung, H.-P.; Lublin, F.D.; Drappa, J.; Barron, G.; Madani, S.; Ratchford, J.N.; She, D.; Cimbora, D.; Katz, E. Inebilizumab for the Treatment of Neuromyelitis Optica Spectrum Disorder (N-MOmentum): A Double-Blind, Randomised Placebo-Controlled Phase 2/3 Trial. Lancet, 0.

9. Doyle KP, Buckwalter MS. Does B Lymphocyte-Mediated Autoimmunity Contribute to Post-Stroke Dementia? Brain Behav Immun. 2017;64:1-8.

10. Filippi M, Bar-Or A, Piehl F, Preziosa P, Solari A, Vukusic S, Rocca MA Multiple Sclerosis. Nat Rev Dis Prim. 2018;4:43.

11. Greenfield AL, Hauser SL. B-Cell Therapy for Multiple Sclerosis: Entering an Era. Ann Neurol. 2018;83:13-26.

12. Hagens MHJ, Killestein J, Yaqub MM, van Dongen GAMS, Lammertsma AA, Barkhof F, van Berckel BNM. Cerebral Rituximab Uptake in Multiple Sclerosis: A89Zr-ImmunoPET Pilot Study. Mult Scler J. 2018;24:543-5.

13. Hartung DM. Economics and Cost-Effectiveness of Multiple Sclerosis Therapies in the USA. Neurotherapeutics. 2017;14:1018-26.

14. Haugen M, Frederiksen JL, Degn M. B Cell Follicle-like Structures in Multiple Sclerosis-With Focus on the Role of B Cell Activating Factor. J Neuroimmunol. 2014;273:1-7.

15. Hauser SL, Waubant E, Arnold DL, Vollmer T, Antel J, Fox RJ, Bar-Or A, Panzara M, Sarkar N, Agarwal S, Langer-Gould A, Smith CH. B-Cell Depletion with Rituximab in Relapsing-Remitting Multiple Sclerosis. N Engl J Med. 2008;358:676-88.

16. Hoehne A, James ML, Alam IS, Ronald JA, Schneider B, D'Souza A, Witney TH, Andrews LE, Cropper HC, Behera D, Gowrishankar G, Ding Z, Wyss-Coray T, Chin FT, Biswal S, Gambhir SS. [(18)F]FSPG-PET Reveals Increased Cystine/ Glutamate Antiporter (Xc-) Activity in a Mouse Model of Multiple Sclerosis. J Neuroinflammation. 2018;15:55.

17. Novich $O$, Natarajan A, Hori S, Sathirachinda A, Kimura R, Srinivasan A, Gebauer M, Kruip J, Focken I, Lange C, Carrez C, Sassoon I, Blanc V, Sarkar SK, Gambhir SS. Development and Validation of an Immuno-PET Tracer as a Companion Diagnostic Agent for Antibody-Drug Conjugate Therapy to Target the CA6 Epitope. Radiology. 2015;276:191-8. 
18. James ML, Hoehne A, Mayer AT, Lechtenberg K, Moreno M, Gowrishankar G, Ilovich O, Natarajan A, Johnson EM, Nguyen J, Quach L, Han M, Buckwalter M, Chandra S, Gambhir SS, Imaging B. Cells in a Mouse Model of Multiple Sclerosis Using ${ }^{64}$ Cu-Rituximab-PET. J Nucl Med. 2017:jnumed.117.189597.

19. Lovato L, Willis SN, Rodig SJ, Caron T, Almendinger SE, Howell OW, Reynolds R, O'Connor KC, Hafler DA. Related B Cell Clones Populate the Meninges and Parenchyma of Patients with Multiple Sclerosis. Brain. 2011; 134:534-41.

20. Lyons J-A, San M, Happ MP, Cross AH. B Cells Are Critical to Induction of Experimental Allergic Encephalomyelitis by Protein but Not by a Short Encephalitogenic Peptide. Eur J Immunol. 1999;29:3432-9.

21. Machado-Santos J, Saji E, Tröscher AR, Paunovic M, Liblau R, Gabriely G, Bien CG, Bauer J, Lassmann H. The Compartmentalized Inflammatory Response in the Multiple Sclerosis Brain Is Composed of Tissue-Resident CD8+ T Lymphocytes and B Cells. Brain. 2018:141:2066-82.

22. Matloubian M, Lo CG, Cinamon G, Lesneski MJ, Xu Y, Brinkmann V, Allende ML, Proia RL, Cyster JG. Lymphocyte Egress from Thymus and Peripheral Lymphoid Organs Is Dependent on S1P Receptor 1. Nature. 2004;427:35560.

23. Michel L, Touil H, Pikor NB, Gommerman JL, Prat A, Bar-Or A. B Cells in the Multiple Sclerosis Central Nervous System: Trafficking and Contribution to CNS-Compartmentalized Inflammation. Front Immunol. 2015;6:1-12.

24. Mitsdoerffer M, Peters A. Tertiary Lymphoid Organs in Central Nervous System Autoimmunity. Front Immunol. 2016;7:1-12.

25. Ortega SB, Torres VO, Latchney SE, Whoolery CW, Noorbhai IZ, Poinsatte K, Selvaraj UM, Benson MA, Meeuwissen AJM, Plautz EJ, Kong X, Ramirez DM, Ajay AD, Meeks JP, Goldberg MP, Monson NL, Eisch AJ, Stowe AM. B Cells Migrate into Remote Brain Areas and Support Neurogenesis and Functional Recovery after Focal Stroke in Mice. Proc Natl Acad Sci. 2020;117:4983-93.

26. Ramanathan S, Dale RC, Brilot F. Anti-MOG Antibody: The History, Clinical Phenotype, and Pathogenicity of a Serum Biomarker for Demyelination. Autoimmun Rev. 2016;15:307-24.

27. Vargas DL, Tyor WR. Update on Disease-Modifying Therapies for Multiple Sclerosis. J Investig Med. 2017;65:883-91.

28. Yi JS, Guptill JT, Stathopoulos P, Nowak RJ, O'Connor KC. B Cells in the Pathophysiology of Myasthenia Gravis. Muscle Nerve. 2018;57:172-84.

\section{Publisher's Note}

Springer Nature remains neutral with regard to jurisdictional claims in published maps and institutional affiliations.

Ready to submit your research? Choose BMC and benefit from:

- fast, convenient online submission

- thorough peer review by experienced researchers in your field

- rapid publication on acceptance

- support for research data, including large and complex data types

- gold Open Access which fosters wider collaboration and increased citations

- maximum visibility for your research: over $100 \mathrm{M}$ website views per year

At $\mathrm{BMC}$, research is always in progress.

Learn more biomedcentral.com/submissions 